\title{
The Impact of Motivation on the Work Performance of Health Workers (Korle Bu Teaching Hospital): Evidence from Ghana
}

\author{
Kofi Aduo-Adjei ${ }^{1, *}$, Odoom Emmanuel ${ }^{1}$, Opoku Mensah Forster ${ }^{1}$ \\ ${ }^{1}$ Department of Public Administration and Health Services Management, Business School, University of Ghana, Accra, Ghana
}

*Corresponding Author: Kofi Aduo-Adjei, MPhil, Department of Public Administration and Health Services Management, School of Business, University of Ghana, Box LG, 78, Accra, Ghana. Tel: +233(0)245896234, Email: aduoadjei@gmail.com

Received: 26 Jan. 2016; Accepted: 15 Mar. 2016; Online Publish: 28 May. 2016

\begin{abstract}
Background: Motivation is a driver to health worker performance in most Ghanaian hospitals. In view of this, Ghana's Ministry of Health has rolled out enough motivational policies to accentuate work performance of health workers.

Objective: The focus of this study was to examine the impact of motivation and identify how intrinsic and extrinsic motivating factors affect the work performance of health workers at Korle-Bu Teaching Hospital (KBTH).

Methods: A qualitative approach was adopted for the study, and purposive sampling was used to select fifteen (15) health workers including both medics and paramedics. An in-depth interview guide and one-on-one interviews were adopted to collect data from the staff at Korle Bu Teaching Hospital. A thematic content analysis was used to analyze the transcribed data.

Results: Key findings from the study revealed that job satisfaction, logistic provision, and an enabling work environment are intrinsic motivating factors that affect the work performance of health workers; extrinsic factors such as financial reward, accommodation, and transportation also impact work performance. Furthermore, motivation is key to the work performance of nurses.

Conclusion: It is recommended that the National Midwifery and Nursing Council (NMC) and the Ministry of Health (MOH) adopt motivational policies based on the intrinsic and extrinsic motivational blocks.
\end{abstract}

Keywords: Motivation, Performance, Intrinsic, Extrinsic

\section{Background}

Motivation is a prerequisite for better organizational performance. Motivation may be described as the processes that account for an individual's intensity, direction, and persistence of effort toward attaining a goal. In most cases, motivation stems from a need which must be fulfilled, and this, in turn, leads to a specific behavior [1]. However, it is not only an inherent factor in individuals, but also a group incentive to act or not to act. It is defined as an intrinsic process that psychologically directs the behavior of an individual [2, 3]. Furthermore, Steers et al. [2] relate motivation to organizational performance. In the healthcare field, attaining health objectives in a population depends to a large extent on the provision of effective, efficient, accessible, viable, and high-quality services by healthcare professionals who, technically, are driven by motivation [1, 4]. In this era, the willingness of employees to work and stay in an organization depends on the extent to which they are adequately motivated [5]. Ideally, every employee will put up a better performance if the incentive packages are rewarding and in line with the capacity to meet the needs of the individual. In this regard, while economic factors play a crucial role in the motivation and retention of healthcare workers, including nurses, in healthcare facilities and other work posts [6], other factors are equally as important to keeping their loyalty. The workforce in the health sector has specific features that cannot be ignored, and motivation can play an integral role in many of the compelling challenges facing healthcare today. Nowadays, the task of motivating is complicated by the nature of the economic relationship between those using the system and the system itself (physicians, patients, and hospitals) and exacerbated by the management of the heterogeneity of the workforce. Some studies contend that health organizations are faced with external pressures that cannot be effectively resolved without appropriate adjustments to the workforce; thus, the development of the workforce appears to be a crucial part of the health policy development process. Motivation as a healthcare policy is an engine for development and growth in all facets of healthcare delivery in Ghana [6, 7]. In Africa, health workers face a hierarchy of motivations or disincentives generated by the work they do, the way they are paid, and the organizational and system context in which they work. Motivational packages are generally designed to encourage providers to furnish specific services, encourage cost containment, support staff recruitment and retention; enhance productivity and the quality of services, and allow for effective management [8, 9].

According to the WHO, the African continent is currently facing a severe human resource crisis in the health sector which appears to have affected the delivery of quality and efficient healthcare services. Sub-Saharan Africa has the lowest health worker-to-population ratio in the whole world $[10,11]$. This trend is getting worse according to countryspecific case studies because of internal and external migration. According to Dieleman et al. [12], the issue of low motivation in the work place is one major contributor to the brain drain of health workers from Africa to other countries and from rural to urban areas within the same country. For decades, researchers have been studying factors influencing performance in health organizations with emphasis on worker and work environment factors. Nurses constitute the largest human resource element in 
healthcare organizations [13] and therefore appear to have a great impact on the quality of care and patient outcomes. Job performance has often been examined in light of work attitudes such as job satisfaction and organizational commitment. Health workers' attitudes toward their jobs and their commitment to their employers have interested researchers because of their impact on behavior at work and quality of patient care. In Saudi Arabia, interest has been growing on issues related to performance in health organizations as a reflection of the increasing interest in quality improvement [14]. Numerous scholars have investigated the performance of health workers in the context of motivation [15-22]. Some studies have focused on the contribution of health workers' care to patient outcomes.

The Herzberg theory states that factors which cause job satisfaction are the opposite of those that cause job dissatisfaction. Herzberg surveyed a group of accountants and engineers and came to the conclusion that employees are influenced by two factors, namely motivators and hygiene factors. Motivators, which include achievement, recognition, autonomy, and other intrinsic aspects, create job satisfaction when an individual is fulfilled. According to Herzberg, motivators pertain to job content; they are intrinsic to the job itself and do not result from "carrot and stick incentives". They comprise the physiological needs for growth and recognition. The absence of these factors does not prove highly dissatisfying, but when present, they build strong levels of motivation that result in good job performance. They are therefore called satisfiers or motivators. These factors include achievement, recognition, advancement, the work itself, the possibility of personal growth, and responsibility. Motivators are those factors that provide a feeling of satisfaction at work and influence the way work is done in a company; for example, giving a person responsibility for a large task within an organization and providing that person with the necessary conditions will lead to his growth and advancement to higher-level tasks. Motivators that are intrinsic are those factors that come from within an individual. These factors could be achievement, interest in the task, responsibility of a large task, growth, and advancement to higher levels. Herzberg's hygiene factors create a suitable work environment, though they will not increase satisfaction. The hygiene factors are also referred to as the maintenance factors and comprise the physiological, safety, and amity needs from Maslow's hierarchy of needs. They are factors not directly related to the job but to the conditions that surround doing the job. They operate primarily to dissatisfy employees when they are not present. However, the presence of such conditions does not necessarily include these factors; company policy and administration, technical supervision, interpersonal relations with supervisor, interpersonal relations with peers and subordinates, salary, job security, personal life, work conditions and status. Herzberg called the abovementioned factors "hygiene factors", since they are necessary to maintain a reasonable level of satisfaction but can also cause dissatisfaction. Hygiene factors are not direct motivators, but they are necessary to prevent dissatisfaction. At the same time, they serve as a starting point for motivation. However, improvements in these conditions do not create the necessary motivation [23]. For instance, low pay can cause job dissatisfaction, which will affect employees' performance on an assigned task. Hygiene factors are essential to ensuring that the work environment does not develop into a disgruntling situation. The basic assumption of Herzberg's two-actor theory indicates that the productivity of health workers on the job can be increased through worker satisfaction, and this comes from a variety of factors. For example, jobs should be challenging enough so that nurses utilize their full ability, and workers who are successful should be given more responsibility. This theory serves as the basis for effective work performance by health workers.

In all human organizations, it is motivation that strengthens, directs, and sustains human behavior [23, 24]. An important addition to these definitions is that motivation may be influenced by factors that are intrinsic or extrinsic to the individual. However, since intrinsic factors are relatively hard to define, emphasis is often placed on the extrinsic factors, which include the ability of managers to satisfy an employee's needs. The sections below explain both intrinsic and extrinsic forms of motivation.

Intrinsic motivation is driven by an interest or enjoyment in the task itself and exists within the individual rather than relying on any external pressure. Intrinsic motivation is the motivation to do or act in one's own interests or simply for the enjoyment of the activity itself [25]. Robbins describes it as the desire to work on something that is interesting, challenging, satisfying, exciting, or involving. Social and educational psychologists have studied intrinsic motivation since the early 1970s [26]. Explanations of intrinsic motivation have been given in the context of Fritz Heider's attribution theory [27], work on self-efficacy [28], and cognitive evaluation theory. Intrinsic motivation is the innate and natural propensity to engage an individual's interests and exercise an individual's skills and capabilities, and, in so doing, to look for and achieve optimal opportunities and challenges [28]. This motivation comes from internal tendencies and can direct and motivate behavior without the presence of constraints or rewards.

Extrinsic motivation comes from outside of the individual. Common extrinsic motivations are rewards like money and grades, coercion, and the threat of punishment. Competition is, in general, extrinsic, because it encourages the performer to win and beat others, not to enjoy the intrinsic rewards of the activity. A crowd cheering for an individual and trophies are also extrinsic incentives. Extrinsic motivation refers to performing an activity with a feeling of being pressured, tension, or anxiety to make sure that one achieves the desired result [29]. Hennessey and Amabile define extrinsic motivation as the motivation to do something to make sure that some external goal is attained or that some external imposed constraint is met. Extrinsically-motivated behaviors are actions that cause the attainment of rewards that are externally imposed, including material possessions, salary, added bonuses, positive feedback and evaluations from others, fringe benefits, and prestige $[30,31]$. Socio-psychological research has indicated that extrinsic rewards can lead to over-justification and a subsequent reduction in intrinsic motivation. In one study demonstrating this effect, children who expected to be (and were) rewarded with a ribbon and a gold star for drawing pictures spent less time playing with the drawing materials in subsequent observations than children who were assigned to an unexpected reward condition and to children who received no extrinsic reward [26]. Motivation is an emotive state causing persons to want or need something intensely enough to put forth the necessary effort to achieve it. 
In Ghana, there has been considerable progress in many health outcome indicators. For instance, the percentage of antenatal and postnatal coverage improved from $42.2 \%$ and $33.8 \%$ in 2008 to $91.3 \%$ and $64.7 \%$ in 2011 respectively. The percentage of maternal deliveries attended by skilled health staff also increased from $44.2 \%$ in 2008 to $52.3 \%$ in 2011. Likewise, the number of outpatient visits per capita improved from 0.77 in 2008 to 1.07 in 2011[32, 33]. However, these achievements were insufficient for attaining the 2015 targets for health-related millennium development goals (MDGs). This is due to a number of factors, including understaffing in health facilities, inequitable distribution of health sector human resources, de-motivated staff and inadequate healthcare infrastructure. Attaining these healthrelated MDGs needs more comprehensive quality improvement interventions, including a health sector human resource (HSHR) approach [13]. There is, therefore, a need to ascertain the influence of motivation on work performance health workers at Korle $\mathrm{Bu}$ Teaching Hospital (KBTH).

\section{Objective}

Some of the extant studies in Ghana on the motivation of healthcare workers are skewed in the quantitative direction. Moreover, some of these studies construct regression models to show the relevant motivation factors that induce high work performance among health workers (30-33). For example, Agyepong studied the relationship between health worker (internal customer) satisfaction and motivation in the public sector in Ghana. Again, Agyepong et al. [34] observed the challenges and policy dimension of the public health workforce in Ghana. A study by Beaglehole and Bonita [35] detailed the policy focus on incentives for rural service among nurses in Ghana. This paper adopted the qualitative approach to further add to the inconclusive studies in the qualitative direction.

\section{Methods}

This study adopted the qualitative research approach. This approach enabled the researcher to carry out an inductive inquiry on motivation and its relationship with work performance. Neuman noted that the qualitative research approach allows for a much more detailed investigation of issues and answering questions of meaning, who is affected (by the issue), why, what factors are involved, and do individuals react or respond differently to each other [36]. In order to describe and give an in-depth analysis and explanation of the dynamics of motivation and work performance of health workers, the study adopted a case study design within the qualitative approach. This design refers to an empirical inquiry that investigates a contemporary phenomenon within its real-life context. The units under study were paramedics, administrators, orderlies, drivers, security officers and medics, nurses, pharmacists, health assistants, and laboratory technicians. A total sample of 15 participants was selected for the study. This sampling technique enabled the researcher to focus on particular characteristics of the population of interest, and this better enabled the researcher to answer the research question. An in-depth view guide was used to collect data and relevant information from the respondents.

\section{Results}

\subsection{Intrinsic Motivation}

The results from the study indicated that health workers have varied opinions as to what the intrinsic factors in the context of work performance are. These factors are job satisfaction, logistic provision, and an enabling work environment.

\subsection{Job Satisfaction}

Job satisfaction is the fulcrum of worker motivation in most service organizations. A satisfied worker has the desire to work hard since inner joy and happiness is the motivating factor for the work. Health workers at KBTH also appreciated job satisfaction has a key drive to work performance. A greater percentage (80\%) of health workers at KBTH highlighted intrinsic motivating factors as the primary drivers to work, as one of the nurses revealed:

". . . I see intrinsic factors as satisfaction, because it is something you like; you have gone to school for it. It is something I have learned to help somebody out of, so I am here because I love the job and I want to help somebody out of his/her problem. That is why I am in this profession, specifically in the midwifery department, and this influences my work performance," (female, senior midwifery officer, aged 35).

\subsection{Logistic Provision}

Other health workers viewed intrinsic motivation in terms of logistics which serve as the boosters for work. They further indicated that these logistics include drugs, consumables, syringes, and infusions to stimulate to hard work. Again, one respondent indicated:

“. . . I see the intrinsic factors as logistics and the things to work with. We don't have the things to work with, such as test kits, and it takes a long time for procurement and stores department to supply us with those things and this really affects work performance" (male, laboratory technician, aged 45).

\subsection{Enabling Work Environment}

Other nurses noted that creating an enabling environment for work performance is what constitutes intrinsic factors other than personal satisfaction. Support from management and other departments is needed for creating a friendly work environment where staff can easily access information on patients to enable quick healthcare delivery, thus eliminating all bureaucratic processes in providing quality healthcare, which is the primary duty of healthcare workers.

“. . . Yes, I get all joy, peace, and satisfaction as a worker at KBTH if the working environment is conducive; thus, one can interact with authorities at all levels, " (male, administrator, aged 32).

\subsection{Extrinsic Motivation}

The findings revealed that health workers indicate there are various forms of extrinsic motivators, including financial reward, accommodation, and transport.

\subsection{Financial Reward}

Health workers at KBTH noted that financial aid is the best motivator for workers in times of financial crisis, and it boosts their work performance. They reported that the new medical superintendent at the hospital started with a 'financial reward', thus a staff is given some monetary rewards for completing a monthly report for his/her department. A senior nurse at the antenatal care unit noted that: 
“. . . The medical superintendents called me and gave me GHC 100 for writing a report on antenatal care attendance. I felt so happy; in fact, next time I will make sure I write a quality report," (female, senior midwifery officer, aged 46).

\subsection{Accommodation and Transport}

Accommodation is relevant for work performance. Some staff noted that they were troubled over this policy and believed that if the hospital had enough accommodation around the hospital, change-over would not be an issue. They also said there would be constant care for patients, where the challenge of long waiting-times for patients because of staff tardiness would be a thing of the past. A greater percentage $(75 \%)$ of the health workers shared this view, as a principal nursing officer revealed:

" . . . some of us reside far away, and with the traffic in town, we waste a lot of time reaching here, and this affects change-overs. We can only afford these houses, because they are quite far. The hospital can build more bungalows or get flats for us so we can be closer to the hospital," (female, principal nursing officer, aged 45).

\section{Discussion}

\subsection{Intrinsic and Extrinsic Motivating Factors of Work Performance}

Motivation is a key determinant of work performance as confirmed by Neuman \& Dickinson [37] and Dartey-Baah \& Amoako [24]; it strengthens, directs, and sustains human behavior. The study findings revealed that intrinsic and extrinsic motivation factors are relevant in influencing the work performance of health workers at KBTH.

\subsection{Intrinsic Motivating Factors}

According to the study, intrinsic motivating factors are relevant to work performance of health workers at the hospital as they revealed that this form of motivation naturally boosts their interest in working hard. Studies have confirmed that motivation factors are innate and natural $[26,28]$; however, they differ based on the profession and the work environment of the employees. The findings indicated that nurses perceived job satisfaction, logistic provisions, and an enabling work environment as key intrinsic motivation factors that influence their work performance at the hospital. These findings agree with those of [38] who reported that intrinsic motivating factors (such as work hours, individual monetary, promotions, age, job satisfaction, and tenure of office) are different and can be anything based on an employee's assertion of work performance.

\subsection{Job Satisfaction}

The staff at KBTH asserted that, intrinsically, job satisfaction is a main drive to work performance as employees enjoy providing healthcare services to patients. These findings correlate with those of Edward \& Ryan [39] who reported that individual satisfaction serves as a motivator to work performance. Again, Weissbein et al. [40] indicated that intrinsic motivation is positively correlated with job satisfaction.

\subsection{Logistics Provision}

The subjective view of nurses on intrinsic motivation is very interesting. Generally, intrinsic motivation has been viewed by most authors in the literature as individual-based satisfaction; however, healthcare workers at KBTH agree with the study of Oudejans [41] that motivated nurses with the needed logistics and the consumables at the hospital have a greater probability of taking care of patients, collaborating, and providing quality healthcare [42].

\subsection{Enabling Work Environment}

According to Yildiz et al. [43], employees are effective at work in an enabling environment. Staff at the hospital sided with this study as they noted that creating an enabling work environment is a form of intrinsic motivation that affects their work performance at the hospital. This finding confirms those of previous studies that indicated a cordial working environment is a motivator to work performance $[44,45]$.

\subsection{Extrinsic Motivating Factors}

External factors are key motivators to nurses, since they share the view that these extrinsic motivators are enablers that boost their work performance as nurses. A study by Adzei \& Atinga [46] indicated that there is a significant correlation between extrinsic motivation and work performance. Staff at KBTH share this view as revealed by Abdulsalam \& Mawoli [47]: extrinsic motivation is a good predictor of work performance in most organizations. There are various forms of extrinsic motivating factors and this includes those discussed below that were mentioned by health workers at KBTH as key to their performance at the hospital.

\subsection{Financial Reward}

Most employees consider monetary gains and rewards the best form of extrinsic motivation [48, 49]. Furthermore, the findings of the study confirm those of a previous study by Lopes [45] that financial incentive is a good extrinsic motivating factor in determining the work performance of a health worker in the ailing economy of Ghana. Staff at this hospital are convinced that such financial rewards are the best form of extrinsic factors since they are able to sort out some miscellaneous expenditures, like transportation and feeding, which affect work performance

\subsection{Accommodation and Transportation}

Accommodation and transportation are major challenges to most employees in Ghana [45]. Staff members at KBTH hospital are also faced with the same challenge. They therefore hinted that accommodation and means of transportation are key determinants that influence their work performance at the hospital. Studies, confirmed that accommodation and means of transportation are retention factors of health workers in rural and other specialized hospitals [50, 51]. Moreover, Lopes [45] noted that most healthcare workers are willing to go and work in deprived communities and urban centers if they are assured of decent accommodations.

\section{Conclusion}

Motivation is a major determinant of work performance for workers in Ghana. Healthcare workers revealed that intrinsic and extrinsic motivational policies have an impact on the work performance of both paramedics and medics at KBTH. Motivation is relevant for organizational performance; thus, a motivated worker is physiologically 
stable, psychologically balanced, and socially minded to effectively perform his/her duties with the needed attention. Motivation is a good thing; if managers and administrators appreciate what drives workers to give an effective work performance, resources will be channeled to get the maximum output from employees. Health workers are motivated by intrinsic and extrinsic factors. Thus, appreciating key financial and nonfinancial motivating factors is relevant for effective work performance among health workers.

\section{Recommendation}

Based on the key findings, it is recommended that the following could have institutional and policy implications. Firstly, the Nursing and Midwifery Council (NMC) of Ghana, the Ministry of Health, and the KBTH should renew their motivational policies content based on the intrinsic and extrinsic motivational blocks. Thus, a motivational approach should target the personal professional-based desire of nurses, such as job satisfaction, logistic provision, and enablingworking environment. Furthermore, policy guidelines aimed at improving the work performances of health workers at KBTH should be introduced. Transportation, accommodation, and an enabling working environment as well as financial rewards are relevant for improving the work performance of health workers at KBTH.

\section{Acknowledgments}

The authors are grateful to the health workers at Korle $\mathrm{Bu}$

Teaching Hospital for their availability for the study.

\section{Authors' Contributions}

All authors contributed significantly towards the study.

\section{Conflict of Interest}

None declared.

\section{References}

1. Lambrou P, Kontodimopoulos N, Niakas D. Motivation and job satisfaction among medical and nursing staff in a Cyprus public general hospital. Hum Resour Health. 2010;8:26. [DOI]

2. Steers RM, Porter LW, Bigley GA. Motivation and leadership at work: McGraw-Hill; 1996.

3. Grafham E, Matheson C, Bond CM. Specialist drug misuse nurse's motivation, clinical decision-making and professional communication: an exploratory study. J Psychiatr Ment Health Nurs. 2004;11(6):690-7. [DOI]

4. Nahavandi A, Malekzadeh AR, Mizzi PJ. Leaders and how they manage. J Bus Strategy. 1991;12(3):47-9. [DOI]

5. Adams O, Hicks V, editors. Pay and non-pay incentives, performance and motivation. WHO's workshop on a Global Health Workforce Strategy, Annecy, France; 2000.

6. Henderson LN, Tulloch J. Incentives for retaining and motivating health workers in Pacific and Asian countries. Hum Resour Health. 2008;6:18. [DOI]

7. Hongoro $\mathrm{C}$, Normand $\mathrm{C}$. Health workers: building and motivating the workforce. 2006.

8. Franco LM, Bennett S, Kanfer R. Health sector reform and public sector health worker motivation: a conceptual framework. Soc Sci Med. 2002;54(8):1255-66. [DOI]

9. Franco M, Haase H. Failure factors in small and medium-sized enterprises: qualitative study from an attributional perspective. Int Entrep Manag J. 2010;6(4):503-21. [DOI]

10. Houston DJ. "Walking the walk" of public service motivation: Public employees and charitable gifts of time, blood, and money. J Public Adm Res Theory. 2006;16(1):67-86. [DOI]

11. Paul F. Health Workers Motivation and the Role of Performance Based Finance Systems in Africa: A Qualitative Study on Health Worker Motivation and the Rwandan Performance Based Finance Initiative in District Hospitals. London School of Economics and
Political Science working paper series. 2009:08-96.

12. Dieleman M, Biemba G, Mphuka S, Sichinga-Sichali K, Sissolak D, van der Kwaak A, et al. 'We are also dying like any other people, we are also people': perceptions of the impact of HIV/AIDS on health workers in two districts in Zambia. Health Policy Plan. 2007;22(3):139-48. [DOI]

13. Alhassan RK, Spieker N, van Ostenberg P, Ogink A, NketiahAmponsah E, de Wit TF. Association between health worker motivation and healthcare quality efforts in Ghana. Hum Resour Health. 2013;11:37. [DOI]

14. Al-Ahmadi H. Factors affecting performance of hospital nurses in Riyadh Region, Saudi Arabia. Int J Health Care Qual Assur. 2009;22(1):40-54. [DOI]

15. Parker PA, Kulik JA. Burnout, self- and supervisor-rated job performance, and absenteeism among nurses. J Behav Med. 1995;18(6):581-99. [DOI]

16. Gauci Borda R, Norman IJ. Factors influencing turnover and absence of nurses: a research review. Int $J$ Nurs Stud. 1997;34(6):385-94. [DOI]

17. Judge TA, Thoresen CJ, Bono JE, Patton GK. The job satisfactionjob performance relationship: a qualitative and quantitative review. Psychol Bull. 2001;127(3):376-407. [DOI]

18. Moneta GB, Siu CM. Trait Intrinsic and Extrinsic Motivations, Academic Performance, and Creativity in Hong Kong College Students. J Coll Stud Dev. 2002;43(5):664-83

19. AbuAlRub RF. Job stress, job performance, and social support among hospital nurses. J Nurs Scholarsh. 2004;36(1):73-8. [DOI]

20. Huang J-J, Tzeng G-H, Ong C-S. Motivation and resourceallocation for strategic alliances through the DeNovo perspective. Math Comput Model. 2005;41(6):711-21. [DOI]

21. Fort AL, Voltero L. Factors affecting the performance of maternal health care providers in Armenia. Hum Resour Health. 2004;2(1):8. [DOI]

22. Mrayyan MT, Modallal R, Awamreh K, Atoum M, Abdullah M, Suliman S. Readiness of organizations for change, motivation and conflict-handling intentions: senior nursing students' perceptions. Nurse Educ Pract. 2008;8(2):120-8. [DOI]

23. Vohs JL, Lysaker PH, Nabors L. Associations of personality with intrinsic motivation in schizophrenia. Psychiatry Res. 2013;208(1):78-80. [DOI]

24. Dartey-Baah K, Amoako GK. Application of Frederick Herzberg's Two-Factor theory in assessing and understanding employee motivation at work: a Ghanaian Perspective. Eur J Bus Manag. 2011;3(9):1-8.

25. Olu Ogunrin F, Ogunrin O, Akerele A. Motivating Nigerian doctors for improved health care delivery. Int J Health Care Qual Assur. 2007;20(4):290-306. [DOI]

26. Hennessey B, Moran S, Altringer B, Amabile TM. Extrinsic and intrinsic motivation. Wiley Encyclopedia of Management. 2005.

27. Robbins SP, Judge T. Essentials of organizational behavior: Prentice Hall Upper Saddle River; 2003.

28. Bandura A. Social cognitive theory of personality. Handbook of personality: Theory and research. 1999:154-96.

29. Amabile TM. Motivational synergy: Toward new conceptualizations of intrinsic and extrinsic motivation in the workplace. Hum Resour Manag Rev. 1993;3(3):185-201. [DOI]

30. Lindenberg S. Intrinsic motivation in a new light. Kyklos. 2001;54(2-3):317-42. [DOI]

31. Deci EL, Ryan RM. The" what" and" why" of goal pursuits: Human needs and the self-determination of behavior. Psychol Inquiry. 2000;11(4):227-68. [DOI]

32. Hornby P, Sidney E. Motivation and Health Systems Performance. WHO, WHO/EDUC/88.196; 1988.

33. Van Lerberghe W, Conceicao C, Van Damme W, Ferrinho P. When staff is underpaid: dealing with the individual coping strategies of health personnel. Bull World Health Organ. 2002;80(7):581-4.

34. Agyepong IA, Anafi P, Asiamah E, Ansah EK, Ashon DA, NarhDometey C. Health worker (internal customer) satisfaction and motivation in the public sector in Ghana. Int $\mathbf{J}$ Health Plann Manage. 2004;19(4):319-36. [DOI]

35. Beaglehole R, Bonita R. Global public health: a new era: Oxford University Press; 2009. [DOI]

36. Lepper MR, Greene D. Turning play into work: Effects of adult surveillance and extrinsic rewards on children's intrinsic motivation. J Pers Soc Psychol. 1975;31(3):479. [DOI]

37. Neuman SB, Dickinson DK. Handbook of early literacy research Guilford Press; 2003.

38. Chaudry J, Jain A, McKenzie S, Schwartz RW. Physician leadership: the competencies of change. J Surg Educ. 2008;65(3):213-20. [DOI]

39. Edward D, Ryan R. Intrinsic Motivation and Self-Determination in 
Human Behavior. New York: Pantheon. 1985.

40. Weissbein DA, Huang JL, Ford JK, Schmidt AM Influencing learning states to enhance trainee motivation and improve training transfer. J Bus Psychol. 2011;26(4):423-35. [DOI]

41. Oudejans R. Linking extrinsic and intrinsic motivation to job satisfaction and to motivational theories: a comparison between the public sector (nurses) and the private sector (call centre agents)(Top Thesis). 2007.

42. Suominen T, Leino-Kilpi H, Merja M, Doran DI, Puukka P. Staff empowerment in Finnish intensive care units. Intensive Crit Care Nurs. 2001;17(6):341-7. [DOI]

43. Yildiz Z, Ayhan S, Erdogmus S. The impact of nurses' motivation to work, job satisfaction, and sociodemographic characteristics on intention to quit their current job: an empirical study in Turkey. Appl Nurs Res. 2009;22(2):113-8. [DOI]

44. Moody RC, Pesut DJ. The motivation to care: application and extension of motivation theory to professional nursing work. J Health Organ Manag. 2006;20(1):15-48. [DOI]

45. Lopes SDF. Destination image: Origins, developments and implications. Pasos. 2011;9(2):305-15.
46. Adzei FA, Atinga RA. Motivation and retention of health workers in Ghana's district hospitals: addressing the critical issues. J Health Organ Manag. 2012;26(4-5):467-85. [DOI]

47. Abdulsalam D, Mawoli MA. Motivation and job performance of academic staff of state universities in Nigeria: the case of Ibrahim Badamasi Babangida University, Lapai, Niger State. Intl J Bus Manag. 2012;7(14):142. [DOI]

48. Chaudry J, Jain A, McKenzie S, Schwartz RW. Physician leadership: the competencies of change. J Surg Educ. 2008;65(3):213-20. [DOI]

49. Mukuma Kyambi J. Influence of Human Resource Diversity Management Practices on Performance of Non-Commercial Government Agencies in Kenya. Kenya: Mukuma Kyambi Justin; 2015.

50. Franko DL, Cousineau TM, Trant M, Green TC, Rancourt D, Thompson D, et al. Motivation, self-efficacy, physical activity and nutrition in college students: randomized controlled trial of an internet-based education program. Prev Med. 2008;47(4):369-77. [DOI]

51. Snir R, Harpaz I, Burke R, Douglas EJ, Morris RJ. Workaholic, or just hard worker? Career Dev Int. 2006;11(5):394-417. [DOI] 